\title{
Effects of vegetation differences in relocated Utah prairie dog release sites
}

\author{
Rachel Curtis*, Shandra Nicole Frey \\ Department of Wildland Resources, Utah State University, Logan, USA; \\ *Corresponding Author: chel.curtis@aggiemail.usu.edu
}

Received 28 March 2013; revised 27 April 2013; accepted 12 May 2013

Copyright (C) 2013 Rachel Curtis, Shandra Nicole Frey. This is an open access article distributed under the Creative Commons Attribution License, which permits unrestricted use, distribution, and reproduction in any medium, provided the original work is properly cited.

\begin{abstract}
Utah prairie dogs have been extirpated in $90 \%$ of their historical range. Because most of the population occurs on private land, this threatened species is continually in conflict with land-owners due to burrowing. The Utah Division of Wildlife Resources has been relocating Utah prairie dogs from private to public land since the 1970s, but relocations have been largely unsuccessful due to high mortality. Utah prairie dogs were relocated in 2010 and 2011 from the golf course in Cedar City, Utah to two prepared sites near Bryce Canyon National Park, Utah. Vegetation transects were established at each site to determine if there was a correlation between site vegetation composition and structure, and Utah prairie dog survival at relocation sites. The vegetation at the two sites was significantly different. One site had significantly less grass cover, more invasive plant cover, and rockier soils. The sites also had different soil structures and long-term Utah prairie dog retention rates. Newly established burrows were clustered rather than randomly distributed. Utah prairie dogs appeared to avoid placing burrows in areas with tall vegetation and rocky soils. More research is needed to determine how site selection determines longterm retention and colonization of a relocation site.
\end{abstract}

Keywords: Burrows; Cynomys Parvidens; Relocation, Reseeding; Utah Prairie Dog; Vegetation Composition; Vegetation Structure

\section{INTRODUCTION}

Utah prairie dogs occur only in southwestern Utah, and have been extirpated in much of their historical range. In the $1920 \mathrm{~s}$ the population was estimated at 95,000 , but by 1972 had declined to 3300 [1] due to factors including introduced sylvatic plague (Yersinia pestis), poisoning, predation, and habitat destruction and degradation [2]. Utah prairie dogs were listed as federally endangered in 1973, but reclassified as threatened in 1984 [1]. In 2010, Utah prairie dog populations numbered approximately 11,000 (spring adult counts). Population recovery is slow due to sylvatic plague outbreaks, and because Utah prairie dogs have slow reproductive and population growth rates [2].

Utah prairie dogs have been relocated from private to public lands since 1972 [1] to increase the prairie dog population in new colonies throughout their historic range. Some removal of prairie dogs is allowed, and relocations are conducted on animals that would otherwise be destroyed. Relocation can also be used as mitigation for development activities under Habitat Conservation Plans [3]. Surviving animals can then be counted toward species recovery. Relocation sites are prepared with artificial burrows and nest boxes prior to release, and predator control is also conducted following relocation. In spite of these efforts, relocations have been largely unsuccessful due to high mortality, and therefore have done little to improve the population status.

Few relocation studies have been conducted on Utah prairie dogs, but some research has been published on relocating black-tailed prairie dogs. Researchers have found that it is very important to place animals in areas with soils conducive to burrowing. Burrows in sandy, rocky, and gravely soils are likely to collapse. Well drained fine sandy loam soils without gravel are favored. Black-tailed prairie dogs are likely to disperse when relocated to areas with poor soil structure [4].

Burrows are used as refugia, and contain nursery chambers for juveniles. Temperatures in burrows are higher in winter, and lower in summer than the surface temperatures. The soil type affects burrow construction, but in black-tailed prairie dogs does not affect burrow density 
[5]. Soils must allow deep burrow systems for overwintering animals [1].

Relocated Utah prairie dogs disperse in a random fashion. Dispersing animals construct shallow temporary burrows, which makes them vulnerable to predation until deep burrow systems are established [1]. It is important that Utah prairie dogs are relocated to a site with a preexisting burrow system, preferably natural burrows [4]. If natural burrows are not available, artificial systems can be created with burrows and nest boxes [6].

Vegetation has been shown to affect burrow densities. Mow and burn treatments create suitable conditions for colony expansion of black-tailed prairie dogs by increasing available habitat and predator visibility. These treatments increase the rate of colony expansion, and influence its direction [7].

For all prairie dog species, grasses are the major component of the diet, although forbs and shrubs are frequently consumed. Invertebrates are not typically consumed, although remains are occasionally found in fecal samples. As with many herbivores, prairie dog diet varies seasonally based on available species [2].

By comparing how frequently a plant was consumed versus how common it was at the site, researchers have been able to determine if a plant species was preferred or avoided by Utah prairie dogs. In a study by Lehmer [8], Utah prairie dogs preferred scarlet globemallow (Sphaeralcea coccinea) and cheatgrass (Bromus tectorum) in each season and elevation. Animals in low elevaions preferentially foraged on western wheatgrass (Elymus smithii), Indian ricegrass (Stipa hymenoides), scarlet globemallow, and needle-and-thread grass (Hesperostipa comata). Mid-elevation animals preferred to forage on cheatgrass and scarlet globemallow, while high elevation animals foraged on wheatgrass species (Elymus spp.), cheatgrass, and sedges (Carex spp.). Utah prairie dogs avoided shrub species such as rubber rabbitbrush (Chrysothamnus nauseosus), Douglas rabbitbrush (Chrysothamnus viscidiflorus), and black sagebrush (Artemisia nova) [8].

Researchers relocating black-tailed prairie dogs suggest that the quality of the release site may influence the survival of relocated animals [9]. Ackers [10] also suggested that release site affects Utah prairie dog survival. We hypothesized that a difference in the grass, forb, and shrub vegetation composition at relocation sites may affect the survival of released animals, such that a large disparity may be correlated with increased emigration from the study site.

\section{METHODOLOGY}

\subsection{Study Area}

Figure 1 shows the location of our 3 study areas. The source Utah prairie dog population was located on the Cedar Ridge Golf Course in Cedar City, Iron County,

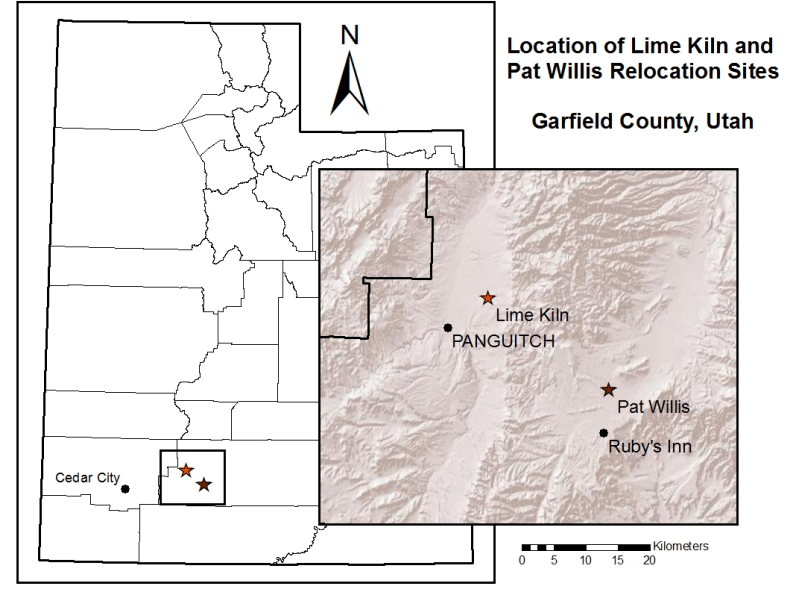

Figure 1. Utah prairie dog study area locations: the source population site at Cedar Ridge Golf Course in Cedar City, Iron County; Lime Kiln and Pat Willis Wash relocation areas.

Utah. In the first year of the study, some animals were also trapped and relocated from additional urban sites, such as baseball fields and equestrian centers, throughout Cedar City. In the second year of the study, all study animals were trapped and relocated from Cedar Ridge Golf Course. The course was roughly $1780 \mathrm{~m}$ in elevation, and received approximately $30 \mathrm{~cm}$ of precipitation annually [11]. Sprinkler irrigation provided supplemental water at the golf course. The course utilized a combination of bluegrass (Poa sp.) and bentgrass (Agrostis sp.), and the dominant soil type at the golf course was loam [12]. Average maximum temperatures ranged from $5.7^{\circ} \mathrm{C}$ in January to $32.3^{\circ} \mathrm{C}$ in July [13].

There were 2 relocation study areas. The first study area, Lime Kiln, was located $8 \mathrm{~km}$ northeast of Panguitch, Garfield County, Utah, and was managed by the US. Bureau of Land Management. In the study area, a $1-\mathrm{km}^{2}$ area of brush was removed, and reseeded using a Great Basin Research Center (Ephraim, Utah) grass and forb seed mix in December of 2008. Dominant recorded plant species included Palmer's penstemon (Penstemon palmeri), blue grama (Bouteloua gracilis), blue flax (Linum lewisii), Indian ricegrass (Stipa hymenoides), needleand-thread (Hesperostipa comata), big sagebrush (Artemisia tridentata), black sagebrush (A. nova), annual mustard, and an assortment of wheatgrass (Elymus) species. During the study, average plant height was $36 \mathrm{~cm}$. Soils ranged from gravelly to very cobbly loam [12]. Panguitch received approximately $25 \mathrm{~cm}$ of precipitation annually [11]. Average maximum temperatures ranged from $4.0^{\circ} \mathrm{C}$ in January to $29.2^{\circ} \mathrm{C}$ in July [13]. Elevation at Lime Kiln was roughly $2080 \mathrm{~m}$.

The Pat Willis study area was in John's Valley north of Ruby's Inn, Garfield County, Utah, and was managed by the US Forest Service. The study area was part of a long drainage of available habitat covering over $10 \mathrm{~km}^{2}$. This 
area had wild prairie dog colonies approximately $500 \mathrm{~m}$ to the south and southeast of the release site, and a release site constructed $1 \mathrm{~km}$ from the current study area in 2011. The Pat Willis study area was historically reseeded with crested wheatgrass (Agropyron christatum). Additional plant species included needle-and-thread, big sagebrush, black sagebrush, rabbitbrush (Chrysothamnus nauseosus), broom snakeweed (Gutierrezia sarothrae), and sedges (Carex spp.). The average plant height was $27 \mathrm{~cm}$, with silty to cobbly loam soils [12]. Bryce Canyon National Park, $17 \mathrm{~km}$ south of the study site received approximately $40 \mathrm{~cm}$ of annual precipitation [11]; average maximum temperatures ranged from $1.4^{\circ} \mathrm{C}$ in January to $26.6^{\circ} \mathrm{C}$ in July [13]. The elevation at Pat Willis Wash was approximately $2330 \mathrm{~m}$.

There were four release sites in each relocation study area. The release sites were greater than $200 \mathrm{~m}$ apart, while each release site contained 5 burrows $4 \mathrm{~m}$ apart. A buried sprinkler box provided a nest chamber, and flexible piping provided 2 entrances for each burrow. Retention cages were placed over each burrow entrance, which also served to protect relocated animals from predators. Water was provided at each site. Predator removal of coyotes (Canis latrans) and badgers (Taxidea taxus) at or near release sites was conducted at both relocation study areas by USDA Wildlife Services, but not at Cedar Ridge Golf Course.

\subsection{Relocation}

Beginning in June 2010, Utah prairie dogs were trapped using single door Tomahawk wire box-traps $(18 \times 18$ $\times 50 \mathrm{~cm}$; Tomahawk Live Trap Company, Hazelhurst, WI) placed near the burrow entrances, and baited with a mixture of peanut butter and sweet oats. Traps were checked each hour to reduce stress to captured animals. The animals were sexed, and weighed using a spring balance. In 2010, prairie dogs as small as $400 \mathrm{~g}$ were relocated. In 2011, all relocated prairie dogs were $550 \mathrm{~g}$ or larger. Trapped prairie dogs were individually eartagged with a different number in each ear. Double tagging reduced the chance of "losing" an animal if a tag was lost. After animals had been weighed and tagged, they were transported to the relocation sites the same day. A maximum of 10 individuals were released in each artificial burrow. Groups typically contained one breeding male, two or three adult females, and the remaining individuals were juveniles of both sexes. We conducted all trapping, marking, and relocation procedures with the Utah Division of Wildlife Resources. Methods were approved by the Institutional Animal Care and Use Committee at Utah State University (IACUC \# 1427).

In mid-September, the Utah Division of Wildlife Resources recaptured the released animals, using the same methods as previous trapping efforts, to determine sur- vival. At each study area, 100 traps were set evenly among release sites and newly constructed natural burrows. There were 8 trap days at each study area, broken into two 4-day sessions, and alternating each week between study areas. When animals were trapped, ear tags were read to identify the trapped animals, and weights were measured using a spring balance.

Recapture data was analyzed in Program MARK [14] to determine if the survival rate varied between relocation study areas. Model significance was established using AICc values to compare the relocation site model to the null model. The first time step interval was determined by calculating the average number of days elapsed between relocation, and the first trap day at that study area. Daily survival and recapture rates were also calculated using Program MARK. Our analysis only included survival from the first 2 months following relocation due to small sample size of relocated prairie dogs trapped a year after relocation.

\subsection{Vegetation Transects}

Vegetation surveys were conducted at each relocation study area in 2011 to determine the effect of vegetation on prairie dog site retention and dispersal. At each study area, we had 30 transects. Each study area was mapped in a $100 \mathrm{~m}$ grid so no two transects overlapped. The necessary number of transects was determined using Dallal's [15] power analysis equation for $80 \%$ power with 0.05 level of significance. The first 15 randomly selected plots were surveyed to provide estimates of means and standard deviation for each site to make the power analysis more accurate.

We established $50 \mathrm{~m}$ transects from a central starting point that ran in a random direction. For each transect, a meter tape was anchored at the $0 \mathrm{~m}$ and $50 \mathrm{~m}$ mark, with the line running as close to the ground as possible. Beginning at the $0 \mathrm{~m}$ mark, we used the line-point intercept method [16], recording any plants that intercepted the wire flag every meter at the canopy, lower, and basal/soil surface layers. Dead and live plants were differentiated in the data. We attempted to identify plants to the species level. Some plants, particularly grasses, were too small to be individually identified and were recorded as annual/ perennial grasses or forbs. This method provided estimates of species composition, percent cover, basal cover, and bare ground [16]. The height of the canopy layer plant was also measured to calculate average vegetation height. Because Utah prairie dogs consume a wide variety of plant species [8] and species composition varied at each site, we focused our analysis on comparing the percent cover of grasses (this included sedges and rushes), forbs, and shrubs, and comparing vegetation height at each site. We did not compare species composition between sites. We created a weed category in the cover ana- 
lysis that included annual mustard, tall annual burrs, Russian thistle (Salsola iberica), and cheatgrass, because these plants contributed little forage, but made up a large percentage of the plants at the Lime Kiln site. At the soil layer, we combined plant species into classes, and included mustard in the forb category. Vegetation height was compared using a two-sample t-test using SAS [17]. Percent cover for each site was calculated using SAS, but compared using a multi-response permutation procedure in Blossom statistical software [18] since percent data has non-normal distribution.

\subsection{Effect on Burrowing Activity}

At the end of the field season, we mapped new burrows in the relocation sites to assess colonization. There were no prairie dog burrows at either site prior to this study. We defined a burrow as a tunnel where we could not see the end of the tunnel from the surface. This eliminated any partially excavated pits the released animals dug.

We used the Average Nearest Neighbor tool in ArcMap [19] to assess the distribution of burrows, and a Hot Spot Analysis tool to compare the burrow locations to vegetation cover values of the vegetation plots.

\section{RESULTS}

\subsection{Relocation}

We trapped and marked 779 Utah prairie dogs in 2010 and 2011. Of the 779 relocated Utah prairie dogs, 50 were retrapped at the release sites during the fall trapping periods. The average number of days between release and retrapping was 56 days (SD: 8.89). Three prairie dogs from the 2010 field season were recaptured in 2011. Two adult females were recaptured in Willis, and one male was trapped in Lime Kiln. Two litters of pups were observed at the Willis site in the spring of 2011. Table 1 shows that there was no difference in survival between the relocation areas 2 months after relocation. However, recapture rate did vary between sites. The Pat Willis site had a recapture rate of 0.509 (SE: 0.041), while the Lime Kiln site's recapture rate was 0.450 (SE: 0.035).

\subsection{Vegetation Transects}

In total, 60 point intercept surveys were collected in 2011. The two sites had significantly different vegetation cover (standardized test statistic $(\mathrm{STS})=-25.174, \mathrm{P} \leq$ 0.001). Figure 2 shows the univariate tests yielded significant results between sites for all plant classes except shrubs. Vegetation height at the Pat Willis site was significantly lower than the Lime Kiln site $(\mathrm{t}=10.530, \mathrm{P} \leq$ 0.001).

Figure 3 shows the cover at the soil surface layer also significantly varied by site (STS $=-20.465, \mathrm{P} \leq 0.001$ ).
Table 1. Utah prairie dog relocation survival models created in Program MARK ranked by corrected Akaike's Information Criterion (AICc).

\begin{tabular}{cccc}
\hline Survival & Recapture & AICc & Model likelihood \\
\hline Null & Site & 861.954 & 1.000 \\
Null & Null & 862.788 & 0.659 \\
Site & Site & 863.952 & 0.368 \\
Site & Null & 864.683 & 0.256 \\
\hline
\end{tabular}

${ }^{*}$ Designates significance by a lower AICc value than the null model.

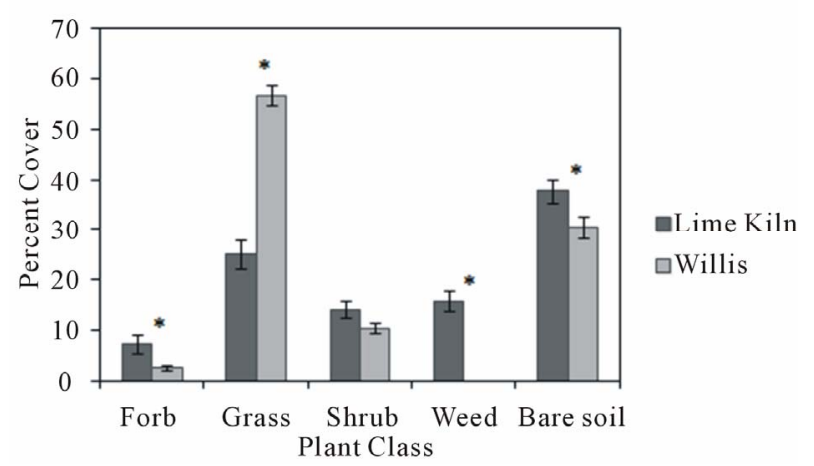

Figure 2. Average cover (\%) of plant classes with standard error bars. Asterisk indicates $\mathrm{P}<0.05$.

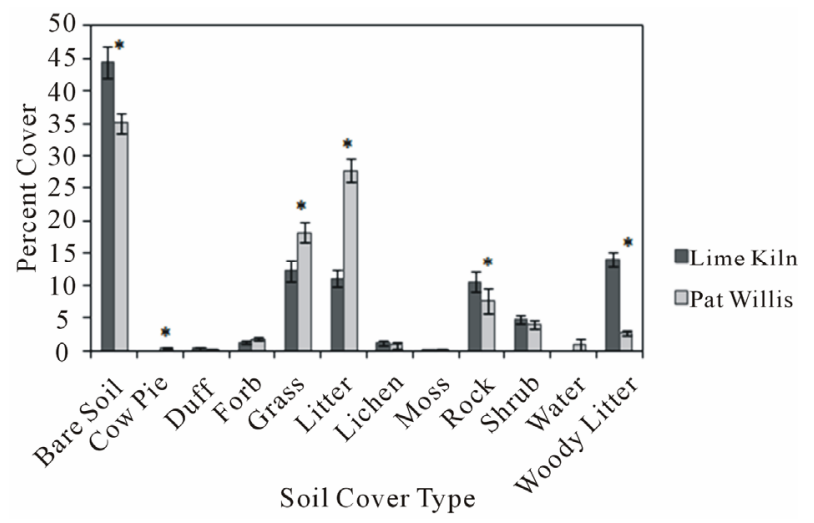

Figure 3. Average cover (\%) of soil surface layer between relocation sites with standard error bars. Asterisk indicates $\mathrm{P}<$ 0.05 .

Univariate tests yielded significant results between sites for all basal cover types except shrubs, moss, lichen, forbs, and fine duff. Water cover was indefinable because a livestock watering pond was recorded in only one transect.

\subsection{Effect on Burrowing Activity}

We found 449 new, natural Utah prairie dog burrows at the relocation areas. Lime Kiln had 143 new burrows, and the Pat Willis site had 306 in the $1-\mathrm{km}^{2}$ area surrounding the relocation sites. Figure 4 shows the new 


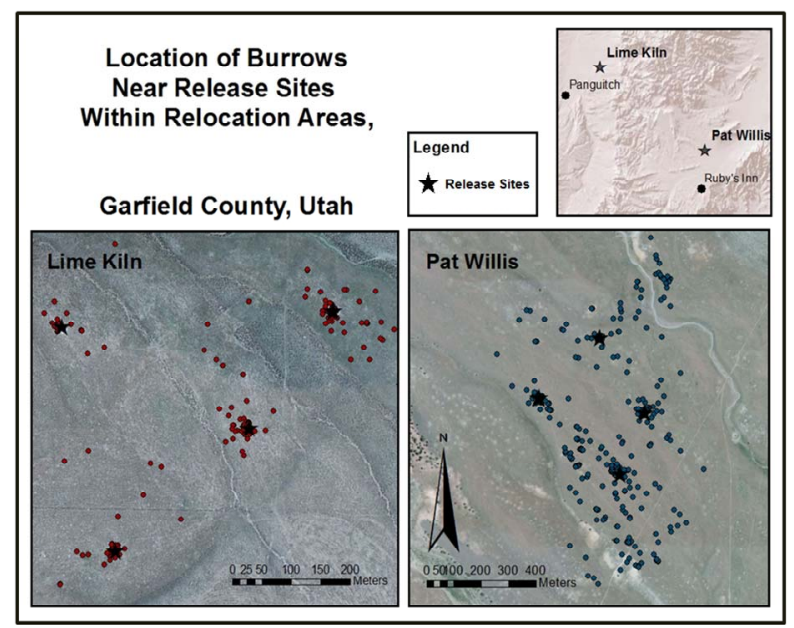

Figure 4. Locations of Utah prairie dog burrows in relation to the release sites within both relocation study areas. Note the larger scale at the Pat Willis site. Locations were mapped in October 2011.

burrows at both sites were clustered rather than randomly distributed. The nearest neighbor tool takes an average distance from each burrow to its closest neighbor. The expected mean represents the average distance burrows would be separated if the burrows were uniformly distributed. At the Lime Kiln site, the observed mean distance between burrows was $16.2 \mathrm{~m}$, while the expected mean was $32.4 \mathrm{~m}(\mathrm{Z}$-score $=-12.900, \mathrm{P} \leq 0.001)$. At the Pat Willis site, the observed mean distance was $14.5 \mathrm{~m}$, while the expected mean was $32.1 \mathrm{~m}(\mathrm{Z}$-score $=-19.547$, $\mathrm{P} \leq 0.001)$.

\section{DISCUSSION}

Although the vegetation characteristics varied significantly between the two relocation sites, this had no apparent effect on site retention 2 months following relocation. However, the Pat Willis site had more Utah prairie dogs 1 year following relocation, relocated animals reproduced the year following release, and more burrows were created than at the Lime Kiln site. There may be several factors driving these trends.

One factor influencing Utah prairie dog survival at relocation sites may be the difference in vegetation height and composition; vegetation was significantly taller at the Lime Kiln site. This may be due to a combination of taller plant species (e.g.: Penstemon palmeri), and higher cattle grazing at the Willis site. Utah prairie dogs have been shown to prefer foraging in short vegetation [20] to avoid predators. The Lime Kiln site had significantly higher percentages of bare soil, weeds, and forbs. The Pat Willis site had a higher percentage of grass than the Lime Kiln Site, and grasses are the preferred forage of prairie dogs $[1,2]$. This could have implications for over winter survival, as variation in hibernation patterns are due to environment rather than physiological differences [21], and suitable forage is necessary for adequate weight gain prior to hibernation [1]. Relocated animals did appear to preferentially forage on grasses and forbs during the summer months, but were observed heavily consuming broom snakeweed (Gutierrezia sarothrae) in the month before hibernation. This was not considered unusual, as prairie dogs are often observed foraging on flowering shrubs during autumn [1].

Woody litter was significantly higher at the Lime Kiln site due to the dead sage brush left from the reseeding treatment in 2008. Deep woody litter may have affected visibility and mobility of relocated prairie dogs avoiding predators. Herbaceous litter was significantly higher at the Willis site, because this category included dead grass. This preferred forage was more common at Willis than Lime Kiln.

Soils were significantly rockier at the Lime Kiln site, which is expected given the gravelly to cobbly loam soil classification of the area. Poor soils may have accounted for the lower number of prairie dog burrows observed at Lime Kiln. Research on black-tailed prairie dogs has shown that dispersal following relocation is significantly higher in areas with poor soil structure [4], and that deep burrow systems are required for overwinter survival [1].

Evaluating burrows on this scale was very subjective. We did not correlate the vegetation characteristics and burrow locations because we were unable to set a distance threshold relating vegetation plots to burrows. It was not uncommon for burrows to be $150-200$ meters from the nearest vegetation plot. Most of the new burrows were clustered around the release sites, particularly at Lime Kiln where there were limited areas with soil conducive to burrowing.

The relocated prairie dogs avoided establishing new burrows in drainages, probably to avoid flooding. They also avoided high, rocky benches. It appeared that the prairie dogs avoided placing burrows in areas with tall vegetation. This preference has been observed in other prairie dog studies $[4,20]$.

\section{SUMMARY}

In this study we were able to determine that site differences may affect the long term retention and colonization of a relocation area. However, evaluating which factors are important for successful relocation sites is beyond the scope of this study. Tall vegetation and rocky soils discouraged prairie dogs from establishing burrows, and sites with reduced suitable forage may have lower retention and reproductive rates. Managers should select relocation sites with a high percentage of grass cover, and soils conducive to burrowing. Additional research should be conducted on the characteristics of historically successful Utah prairie dog relocation sites. 


\section{ACKNOWLEDGEMENTS}

The authors would like to thank the Utah Division of Wildlife Resources and the Bureau of Land Management for funding this research. We thank the Utah Division of Wildlife Resources for logistical and field support. We also thank M. Conover and C. Call for review comments, and S. Durnham for statistical assistance. We thank N. Brown, A. Kavalunas, J. Sorensen, C. Westfall, S. Myers, C. Cardinal, S. Bardot, and the Red Hills Golf Course staff for their time and efforts on this project.

\section{REFERENCES}

[1] US Fish and Wildlife Service (1991) Utah prairie dog recovery action plan. Prepared in cooperation with the Utah Division of Wildlife Resources, Denver.

[2] Slobodchikoff, C.N., Perla, B.S. and Verdolin, J.L. (2009) Prairie dogs: Communication and community in an animal society. Harvard University Press, Cambridge.

[3] US Fish and Wildlife Service (2009) Utah prairie dog (Cynomys parvidens) draft revised recovery plan. Denver.

[4] Roe, K.A. and Roe, C.M. (2003) Habitat selection guidelines for black-tailed prairie dog relocations. Wildlife Society Bulletin, 31, 1246-1253.

[5] Hoogland, J.L. (1995) The black-tailed prairie dog. University of Chicago Press, Chicago.

[6] Truett, J.C., Dullum, J.A.L.D., Matchett, M.R., Owens, E. and Seery, D. (2001) Translocating prairie dogs: A review. Wildlife Society Bulletin, 29, 863-872.

[7] Northcott, J., Andersen, M.C., Roemer, G.W., Fredrickson, E.L., DeMers, M., Truett, J. and Ford, P.L. (2008) Spatial analysis of effects of mowing and burning on colony expansion in reintroduced black-tailed prairie dog (Cynomys ludocicianus). Restoration Ecology, 16, 495-502. doi:10.1111/j.1526-100X.2007.00323.x

[8] Lehmer, E.M., Biggins, D.E. and Antolin, M.F. (2006) Forage preferences in two species of prairie dog (Cynomys parvidens and Cynomys ludovicianus): Implications for hibernation and facultative heterothermy. Journal of Zoology, 269, 249-259.

[9] Bly-Honness, K., Truett, J.C. and Long, D.H. (2004) In- fluence of social bonds on post-release survival of translocated black-tailed prairie dogs (Cynomys ludovicianus). Ecological Restoration, 22, 204-209. doi:10.3368/er.22.3.204

[10] Ackers, S.H. (1992) Behavioral responses of Utah prairie dogs (Cynomys parvidens) to translocation. Masters Thesis, Utah State University, Logan.

[11] Western Regional Climate Center (2011) Desert Research Institute, Reno. http://www.wrcc.dri.edu/htmlfiles/ut/ut.ppt.html

[12] Soil Survey Staff (2012) Natural Resources Conservation Service, United States Department of Agriculture. Web Soil Survey. http://websoilsurvey.nrcs.usda.gov/

[13] Western Regional Climate Center (2011) Desert Research Institute, Reno. http://www.wrcc.dri.edu/summary/Climsmut.html

[14] Program MARK (2010) Version 6.0. http://warnercnr.colostate.edu/ gwhite/mark/mark.htm

[15] Dallal, G.E. (1997) Sample size for controlled trials. http://www.jerrydallal.com/LHSP/SIZE.HTM

[16] Herrick, J.E., Van Zee, J.W., Havstad, K.M., Burkett, L.M. and Whitford, W.G. (2009) Monitoring manual for grassland, shrubland, and savanna ecosystems. Volume 1: Quick start. The University of Arizona Press, Tuscon.

[17] SAS Statistical Software (2011) SAS Institute Inc. Cary.

[18] Blossom Statistical Software (2012) Version W2008.04.02. Fort Collins. www.fort.usgs.gov/Products/Software/Blossom

[19] Environmental Systems Research Institute (2010) ArcGIS ArcMap Version 10.0. Redlands.

[20] Cheng, E. and Ritchie, M.E. (2006) Impacts of simulated livestock grazing on Utah prairie dogs (Cynomys parvidens) in a low productivity ecosystem. Oecologia, 147, 546-555. doi:10.1007/s00442-005-0286-y

[21] Lehmer, E.M. and Biggins, D.E. (2005) Variation in torpor patterns of free-ranging black-tailed and Utah prairie dogs across gradients of elevation. Journal of Mammalogy, 86, 15-21. doi:10.1644/1545-1542(2005)086<0015:VITPOF $>2.0 . \mathrm{C}$ $\underline{\mathrm{O} ; 2}$ 